\title{
TU/e EmonOWEN

\section{Time delayed collection field experiments on polymer: fullerene bulk-heterojunction solar cells}

\section{Citation for published version (APA):}

Offermans, T., Meskers, S. C. J., \& Janssen, R. A. J. (2006). Time delayed collection field experiments on polymer: fullerene bulk-heterojunction solar cells. Journal of Applied Physics, 100(7), 74509-1/7. [74509]. https://doi.org/10.1063/1.2356783

DOI:

$10.1063 / 1.2356783$

Document status and date:

Published: 01/01/2006

\section{Document Version:}

Publisher's PDF, also known as Version of Record (includes final page, issue and volume numbers)

\section{Please check the document version of this publication:}

- A submitted manuscript is the version of the article upon submission and before peer-review. There can be important differences between the submitted version and the official published version of record. People interested in the research are advised to contact the author for the final version of the publication, or visit the $\mathrm{DOI}$ to the publisher's website.

- The final author version and the galley proof are versions of the publication after peer review.

- The final published version features the final layout of the paper including the volume, issue and page numbers.

Link to publication

\section{General rights}

Copyright and moral rights for the publications made accessible in the public portal are retained by the authors and/or other copyright owners and it is a condition of accessing publications that users recognise and abide by the legal requirements associated with these rights.

- Users may download and print one copy of any publication from the public portal for the purpose of private study or research.

- You may not further distribute the material or use it for any profit-making activity or commercial gain

- You may freely distribute the URL identifying the publication in the public portal.

If the publication is distributed under the terms of Article 25fa of the Dutch Copyright Act, indicated by the "Taverne" license above, please follow below link for the End User Agreement:

www.tue.nl/taverne

Take down policy

If you believe that this document breaches copyright please contact us at:

openaccess@tue.nl

providing details and we will investigate your claim. 


\title{
Time delayed collection field experiments on polymer: Fullerene bulk-heterojunction solar cells
}

\author{
Ton Offermans, Stefan C. J. Meskers, ${ }^{\text {a) }}$ and René A. J. Janssen \\ Molecular Materials and Nanosystems Group, Department of Chemical Engineering and Chemistry, \\ Eindhoven University of Technology, P.O. Box 513, 5600 MB Eindhoven, The Netherlands \\ and Dutch Polymer Institute (DPI), P.O. Box 902, 5600 AX Eindhoven, The Netherlands
}

(Received 24 May 2006; accepted 21 June 2006; published online 12 October 2006)

\begin{abstract}
The recombination of photogenerated charge carriers in poly[2-methoxy-5-(3',7'-dimethyloctyloxy)-1,4-phenylene vinylene]:1-(3-methoxycarbonyl)-propyl-1-phenyl-[6,6]C 61 bulk-heterojunction solar cells is investigated using the time delayed collection field technique. Here the lifetime of photogenerated electrons and holes that have escaped charge recombination can be determined from current measurements using a pulsed collection voltage that is delayed with respect to the excitation pulse. At $80 \mathrm{~K}$, the number of long lived charge carriers decays in time according to $t^{-\alpha}$ with $\alpha=0.2$, practically independent of laser fluence in the range of $1-1000 \mu \mathrm{J} / \mathrm{cm}^{2}$. For excitation density $<4 \mu \mathrm{J} / \mathrm{cm}^{2}$ the number of long lived carriers $\left(n_{L}\right)$ depends linearly on the fluence. At higher fluence, $n_{L}$ is limited by a process that occurs in the time span between generation and carrier extraction under a constant bias $(-4 \mathrm{~V})$. Continuous background illumination reduces the lifetime of long lived carriers, probably by filling the low energy trap sites, for which a number density of $10^{17} \mathrm{~cm}^{-3}$ is estimated. Recombination of long lived carriers at $80 \mathrm{~K}$ in the $1-1000 \mu \mathrm{s}$ range is not limited by the (bimolecular) rate of nongeminate electron and hole encounter. Instead, the rate is limited by a monomolecular process, which may be the detrapping of one type of carrier or the recombination within a Coulombically bound electron-hole pair. (C) 2006 American Institute of Physics. [DOI: 10.1063/1.2356783]
\end{abstract}

\section{INTRODUCTION}

Bulk-heterojunction polymer solar cells use a nanoscopically phase-separated blend of an electron donating and an electron accepting material as the active layer. ${ }^{1,2}$ When light is absorbed in the active layer by either of the two components, a photoinduced charge transfer across the interface can produce a geminate electron-hole pair. Provided that percolation pathways exist to the two electrodes, the photogenerated electrons and holes may be collected in an external circuit before they recombine. State-of-the-art polymer solar cells provide high yields $(50 \%-80 \%)$ for collected charges with respect to the incident photons under short circuit conditions. $^{3-5}$

The mechanism of the dissociation of photogenerated geminate electron-hole pairs at the interface of the two materials in the active layer of these devices is presently not completely understood. The polymers and molecular materials used typically have a low dielectric constant $\left(\varepsilon_{r}=3-4\right)$ and therefore one estimates the dissociation energy for an electron-hole pair with $\sim 1 \mathrm{~nm}$ distance between the charges $(0.4 \mathrm{eV})$ to be considerably larger than the thermal energy. This simple evaluation suggests that photogenerated charge carriers have a tendency to form Coulombically bound electron-hole pairs across the donor-acceptor interface. Experimental support for this notion has come from the observation of exciplex luminescence in polymer-polymer bulk heterojunctions. ${ }^{6,7}$

For the well studied poly[2-methoxy-5-(3', 7'-dimethyl-

${ }^{a)}$ Electronic mail: s.c.j.meskers@tue.nl octyloxy)-1,4-phenylene vinylene]:1-(3-methoxycarbonyl)propyl-1-phenyl-[6,6]C 61 (MDMO-PPV:PCBM) [Fig. 1(a)] bulk heterojunction, experimental evidence for the existence of Coulombically bound electron-hole pairs across the donor-acceptor interface is scarce. ${ }^{8,9}$ Investigating the recombination of photoinduced charges can provide additional insight. If the charges are present in the form of a Coulomb pair, one expects the decay to be monomolecular, i.e., independent of the excitation density. Instead, if "free" carriers are generated, the recombination kinetics may be expected to depend on the excitation density (bimolecular decay).

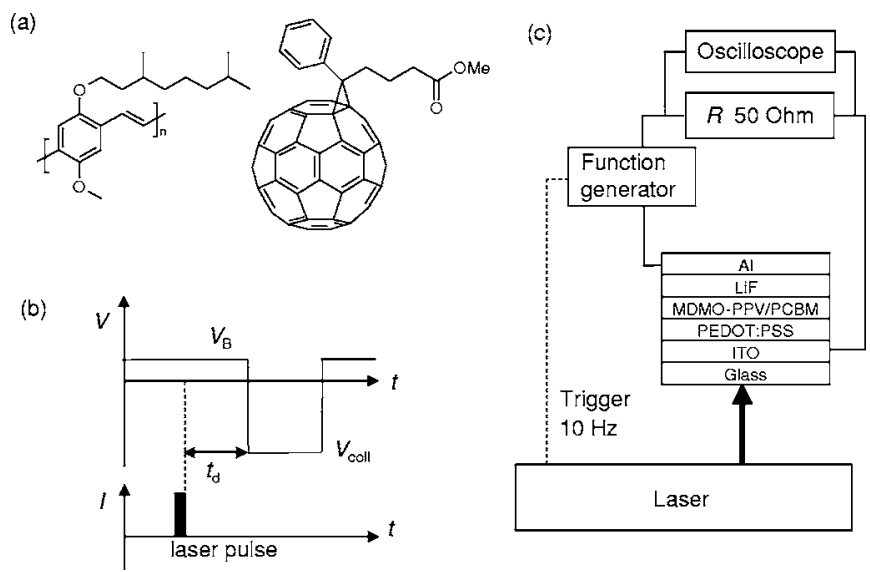

FIG. 1. (a) Compounds used MDMO-PPV (poly[2-methoxy-5-(3', $7^{\prime}-$ dimethyloctyloxy)-1,4-phenylene vinylene]) and PCBM (1-(3methoxycarbonyl)-propyl-1-phenyl-[6,6] $\mathrm{C}_{61}$ ). (b) Principle of the TDCF technique and timing of voltage and laser excitation pulses. (c) Sketch of the experimental TDCF setup for solar cell devices. 
Recently, the recombination dynamics of photogenerated charge carriers in photovoltaic devices consisting of a thick layer $(260 \mathrm{~nm})$ of MDMO-PPV:PCBM have been measured using the photo-CELIV (charge extraction by a linearly increasing voltage) technique. ${ }^{10-12}$ In the photo-CELIV technique, ${ }^{13,14}$ charge carriers are generated by a short illumination pulse and after a variable delay a linearly increasing voltage is applied to extract charges from the device. The method allows for determination of the number of carriers surviving up to the delay time and their mobility. Clear evidence for bimolecular recombination at room temperature was obtained indicating that the long lived $\left(\tau>10^{-6} \mathrm{~s}\right)$ carriers, which can be extracted at room temperature, are not present as Coulombically bound electron-hole pairs. The CELIV measurements at low temperature $(120 \mathrm{~K})$ show that the decay of the number of extracted carriers is no longer proportional to $\left[1+\left(t / t_{0}\right)\right]^{-1}$ as expected for bimolecular recombination of unbound electrons and holes. ${ }^{12}$ Instead the decay becomes dispersive and is proportional to $\left[1+\left(t / t_{0}\right)^{\alpha}\right]^{-1}$. This has been explained in terms of a time dependent mobility of the charge carriers leading to a time dependent bimolecular recombination rate. ${ }^{12}$

A complicating factor in the description of the recombination process is the internal structure of the bulk heterojunction. Microscopy studies of 1:4 wt \% MDMO-PPV:PCBM blends spin cast from chlorobenzene have shown phase separation with a feature size of about $10-100 \mathrm{~nm}$, comparable to film thickness. The films consist of an almost pure nanocrystalline PCBM phase and a second phase that comprises MDMO-PPV and PCBM in an almost equal weight ratio. ${ }^{15} \mathrm{It}$ may be assumed that the long lived electrons and holes reside in, respectively, the PCBM and the mixed polymer phase. The recombination, which probably takes place at the interface of the two phases, occurs with a rate constant that is determined by the mobility of the slowest carrier. ${ }^{16}$ At low temperature, where the long lived carriers may be expected to be strongly trapped on low energy sites, the recombination may even be rate limited by the detrapping of the charge carriers required for motion towards the interface.

In the Langevin description of bimolecular recombination it is assumed that electrons and holes recombine very rapidly once diffusive motion has reduced the distance between them to the Onsager radius $\left[r_{C}=e^{2} /\left(4 \pi \varepsilon_{0} \varepsilon_{r} k_{B} T\right)\right]$ or smaller. This then implies that the carriers can no longer be retrieved by application of a voltage pulse or contribute to the photoinduced absorption. At low temperature $(80 \mathrm{~K}), r_{C}$ amounts to $50 \mathrm{~nm}$ for a medium with relative dielectric constant of $\varepsilon_{r}=4$. At low temperature the possibility exists that either direct photoexciation or diffusive motion results in formation of Coulombically bound electron-hole pair and that the recombination within these pairs is very slow. Carriers, when present in such a pair, may still be extracted by a collection pulse or contribute to the induced absorption. The decay within the Coulombically bound pair will be monomolecular. How likely is formation of long lived electron-hole pairs at low temperature? In experiments using a nanoseconds light pulse for charge carrier generation, the laser fluence is typically $1 \mu \mathrm{J} / \mathrm{cm}^{2}$ resulting in formation of $10^{2}$ charge pairs in a spherical volume with $r=r_{C}$. Thus, if all geminate charge pairs dissociate, there will be plenty of carriers within the Onsager distance of a particular carrier to form a pair.

Studies on long lived carriers relying on electrical extraction may give results that are not representative for all charge carriers as some of them may not be extractable at all. Recombination kinetics can also be studied optically, detecting charges by time-resolved photoinduced absorption measurements. ${ }^{17-20}$ These measurements have shown a power law type of decay $\left(\propto t^{-\alpha}, \alpha \approx 0.4\right)$ with a slope $\alpha$ independent of the excitation density. The CELIV measurements at room temperature show a decay profile that differs from the power law decay observed by photoinduced absorption measurements and a possible explanation for this difference is that in the CELIV technique the deepest trapped charge carriers are not extracted, whereas in time-resolved photoinduced absorption measurements also the deepest trapped carriers are detected. ${ }^{10}$

Here we investigate the recombination of photogenerated electrons and holes in the MDMO-PPV:PCBM blend at low temperature $(80 \mathrm{~K})$ in the $1-10^{4} \mu$ s time range using excitation fluences from 1 to $1000 \mu \mathrm{J} / \mathrm{cm}^{2}$. We use the time delayed collection field (TDCF) method ${ }^{21-28}$ to extract and count the number of long lived charges. In this technique a delayed voltage pulse with constant height is used to extract long lived carriers. This method is simpler than the CELIV method referred to above, but can be applied to solar cell devices with $100 \mathrm{~nm}$ thickness, which is close to optimal for photovoltaic performance. In the TDCF technique a field is applied that is large enough to sweep out charge carriers that have been generated by a short laser pulse [Fig. 1(b)]. By delaying this collection field in time with respect to the laser pulse, the recombination kinetics of the photogenerated charges can be followed.

The prime motivation for studying the recombination of long lived carriers at low temperature $(80 \mathrm{~K})$ and variable excitation density is that observation of intensity dependent decay rates (bimolecular decay) provides direct evidence for the presence of charges that are not electrostatically bound to a charge of opposite sign. If this type of charge carrier is indeed generated at low temperature, it would imply that the Coulomb force is of little importance in the solar cell performance at least for the carriers probed by the extraction methods. A further goal of this study is to compare results from the TDCF method with decay profiles obtained from photoinduced absorption spectroscopy and assess whether the extraction and optical detection method effectively probe subsets of all the photogenerated charge carriers.

\section{EXPERIMENT}

In the TDCF experiment, a collection pulse is applied to the photovoltaic device with a variable delay after pulsed photoexcitation [Fig. 1(b)]. Photoexcitation was performed with $2.76 \mathrm{eV}$ photons (pulse width of $4 \mathrm{~ns}$, repetition rate of $10 \mathrm{~Hz}$ ) obtained from an optical parametric oscillator, pumped by the third harmonic of a Nd-YAG (yttrium alu- 
minium garnet) laser. Background illumination, covering the entire device area, was generated by a tungsten-halogen lamp at excitation densities up to $0.8 \mathrm{~W} / \mathrm{cm}^{2}$.

The photovoltaic devices used, consist of an indium tin oxide (ITO) coated glass substrate, followed by a $100 \mathrm{~nm}$ spin-coated poly $(3,4-e t h y l e n e d i o x y t h i o p h e n e)$ : poly(styrenesulfonic acid) (PEDOT:PSS) layer, a $100 \mathrm{~nm}$ spin-coated layer of a 1:4 weight ratio mixture of MDMO-PPV:PCBM solution from chlorobenzene, a $1 \mathrm{~nm} \mathrm{LiF}$ layer, and a $150 \mathrm{~nm}$ aluminum electrode. The active device area was $0.2 \mathrm{~cm}^{2}$ of which $0.07 \mathrm{~cm}^{2}$ was illuminated. During measurements the device was held in a dynamic vacuum. The effective optical density of the molecular layer for $2.76 \mathrm{eV}$ photons is estimated at 0.6 from measurements of the intensity of the light that is reflected at the metal back electrode.

The Nd-YAG laser triggers an Agilent 33250A function generator that is used to generate a collection pulse [temporal width of $150 \mu$ s, see Fig. 1(c)]. The bandwidth of the function generator $(30 \mathrm{MHz})$ is much higher than the inverse $R C$ time of the device (see below), so that the latter determines the time resolution. Positive bias voltage corresponds to the ITO electrode being charged positively with respect to the $\mathrm{Al}$ electrode. A Tektronix TDS5052B digital oscilloscope is used to measure the voltage over a $50 \Omega$ resistance placed in series with the photovoltaic device [Fig. 1(c)]. The measured transients were averaged over up to 1000 acquisitions.

\section{RESULTS AND DISCUSSION}

\section{A. Experimental parameters for TDCF}

Before we discuss the results on photovoltaic cells, we briefly address the parameters of the extraction voltage pulse used in the TDCF measurement. In the experiment, a rectangular voltage pulse with height, $V_{\text {coll }}$, is applied to the photovoltaic device and the current is measured by recording the voltage over a resistor using an oscilloscope [Fig. 1(c)]. The voltage pulse has an onset at time $t=t_{d}$ and is delayed with respect to the laser pulse $(t=0)$. The delay between the two pulses is variable. In Fig. 2(a) we show two current traces; one recorded with the laser pulse striking the device and one where the light beam is blocked. A schematic representation of the traces is given in Fig. 2(b) for clarity. With the laser blocked, the trace shows a negative peak at the onset of the collection pulse (at time $t_{d}$ ) and an equally large positive response when the collection field turns off. This response is capacitive in origin ${ }^{29}$ and the $R C$ time of the device can be determined $(\sim 3 \mu \mathrm{s})$. When the laser is on, an additional contribution to the current is measured near $t=t_{d}$, which is due to extraction of photogenerated charges. These charges must have survived recombination and extraction in the time interval from $t=0$ to $t=t_{d}$. To obtain the number of extracted carriers the difference between laser on and off traces is integrated over time.

Around $t=0$ a small photocurrent is observed that is due to carriers which are driven out of the active layer by the internal electric filed of the device. An external bias voltage $V_{B}$ is applied [Figure 1(b)] in order reduce this direct photocurrent. Figure 3(a) shows the influence of $V_{B}$ on the (a)

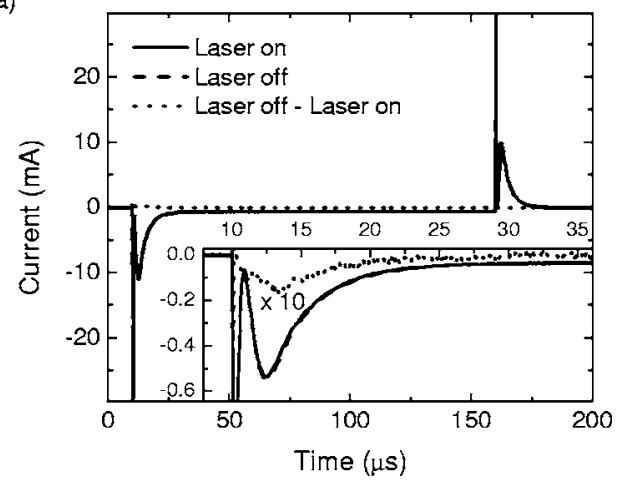

(b)

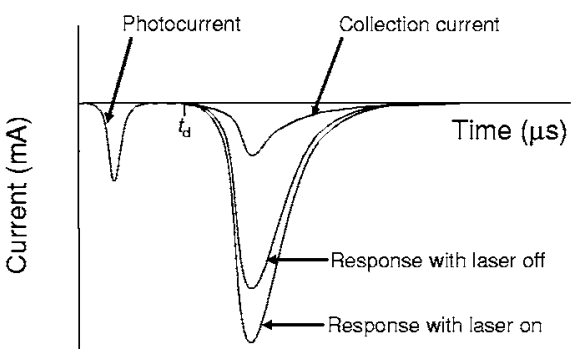

FIG. 2. (a) Measured current traces in the TDCF experiment. Optical excitation was at $t=0$; the collection field was turned on at $t_{d}=10 \mu$ s. The device was kept close to $V_{\mathrm{OC}}$ reducing the photocurrent. The inset shows a magnification of the first $40 \mu \mathrm{s}$. (b) Sketch of the current through the device, with and without laser excitation.

photocurrent yield at $80 \mathrm{~K}$ (the yield is calculated as the percentage of collected electrons around $t=0$ per incident photon). Applying a bias of $V_{B}=+1.08 \mathrm{~V}$ minimizes the photocurrent at $80 \mathrm{~K}$ effectively, and this bias voltage will be used in the TDCF experiments to prevent loss of carriers before the collection pulse. As expected, $V_{B}$ is close to the open-circuit voltage $V_{\mathrm{OC}}$ at this temperature.

Figure 3(b) shows the yield of delayed carrier collection as a function of $V_{\text {coll }}\left(80 \mathrm{~K}, t_{d}=10 \mu \mathrm{s}\right)$. A constant bias $V_{B}$ $=+1.08 \mathrm{~V}$ was kept on the device during excitation. The yield approaches saturation below $-3 \mathrm{~V}$. This indicates effective extraction of charges and the measurements have been carried out with $V_{\text {coll }}=-4 \mathrm{~V}$. As can be seen in Fig. 2(a), using $V_{\text {coll }}=-4 \mathrm{~V}$, the majority of the carriers is extracted within $10 \mu \mathrm{s}$. Thus the temporal width of the collection pulse of $150 \mu$ s should be sufficiently long to capture as many carriers as possible.

\section{B. TDCF experiments on MDMO-PPV:PCBM solar cells}

To investigate the recombination kinetics at low temperature we have determined the number of extracted carriers for various time delays and as a function of laser fluence [Fig. 4(a)]. Also the yield of carrier collection (number of carriers extracted per incident photon) is given [Fig. 4(b)]. First we discuss the yield of carrier collection upon application of a constant of $-4 \mathrm{~V}$ bias during excitation and collection. At fluences smaller than $4 \mu \mathrm{J} / \mathrm{cm}^{2}$, the number of charges collected increases linearly with the excitation intensity indicating that the promptly extracted carriers are not subject to nongeminate recombination with other photoge- 

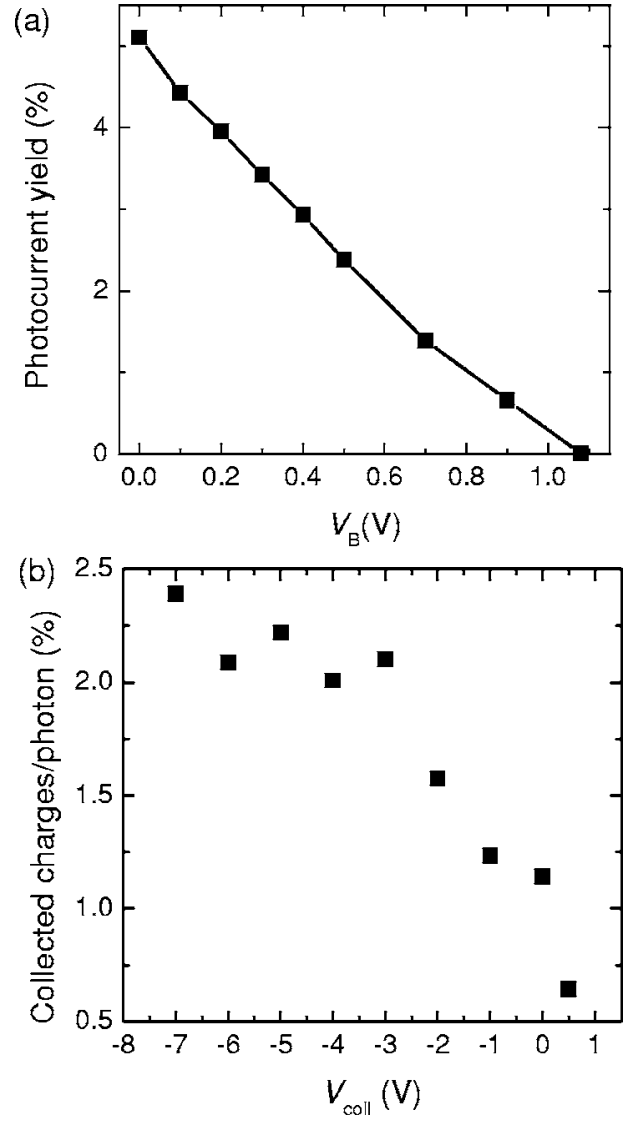

FIG. 3. TDCF experiments of MDMO-PPV:PCBM at $80 \mathrm{~K}$ with an excitation fluence of $4 \mu \mathrm{J} / \mathrm{cm}^{2}$. (a) Photocurrent yield for different constant applied bias voltages $V_{B}$ during pulsed laser illumination. (b) Collected charges per incident photon for different collection pulse voltages $V_{\text {coll }}$ with $V_{B}=+1.08 \mathrm{~V}$ at $t_{d}=10 \mu \mathrm{s}$.

nerated charge carriers. At higher fluences, the number of collected charges levels off and approaches saturation.

With $V_{B}=+1.08 \mathrm{~V}$ during a $10 \mu$ s delay before applying $V_{\text {coll }}=-4 \mathrm{~V}$, the yield of carriers is an order of magnitude smaller than with a constant of $-4 \mathrm{~V}$ bias. Thus about $90 \%$ of carriers have recombined within $10 \mu$ s after excitation, but the fluence dependence of the yield with delayed and prompt extraction are remarkably similar. This similarity indicates that the recombination taking place in the first $10 \mu \mathrm{s}$ is not limited by the rate of bimolecular nongeminate electron-hole encounter. If bimolecular recombination would be rate limiting under these conditions, the yield at high pump fluences should have been less in the second experiment. The result therefore implies that rate must be limited by a monomolecular step. The same conclusion holds for the charges extracted with longer delays (100 and $1000 \mu \mathrm{s})$.

The decay of the number of extractable carriers in time was studied in more detail for two excitation densities (Fig. 5). At $4 \mu \mathrm{J} / \mathrm{cm}^{2}$ fluence, the yield of collected charges decreases according to a power law $\left(\sim t^{-\alpha}\right)$ with an exponent of $\alpha=\sim 0.18$ between $1 \mu \mathrm{s}$ and $10 \mathrm{~ms}$ after excitation. This holds for both $V_{B}=1.08 \mathrm{~V}$ and $V_{B}=0 \mathrm{~V}$. This indicates that the small electric field in the device that exists when $V_{B}$ $=0 \mathrm{~V}$ at $0<t<t_{d}$ is too weak to sweep out the long lived $(>1 \mu \mathrm{s})$ photogenerated charges at $80 \mathrm{~K}$.

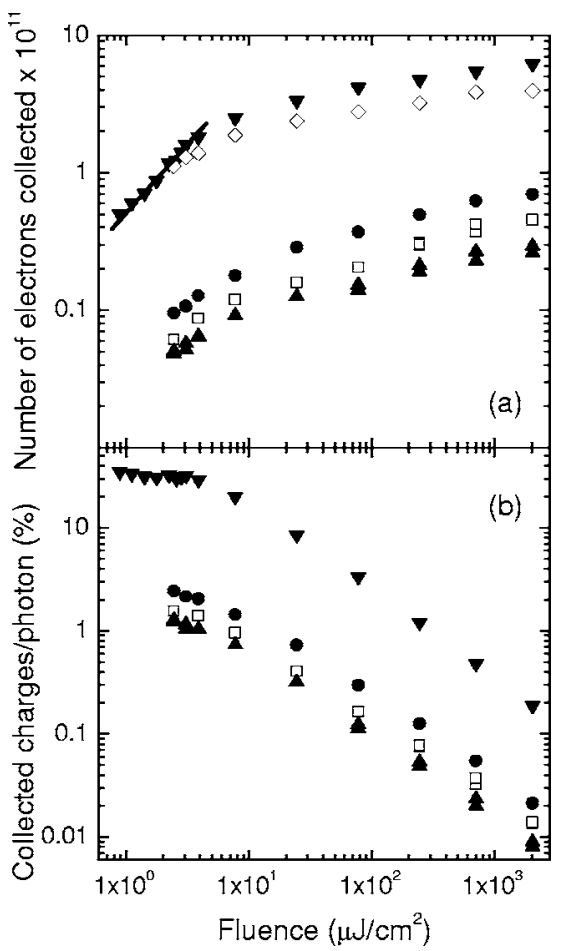

FIG. 4. Fluence dependence of (a) the number of charges collected and (b) the collected charges per incident photon. Data are shown for a constant dc bias of $-4 \mathrm{~V}$ at $80 \mathrm{~K}(\boldsymbol{\nabla})$ and $295 \mathrm{~K}(\diamond)$, and for TDCF experiments at $80 \mathrm{~K}$ for delay times of $10 \mu \mathrm{s}(\bullet), 100 \mu \mathrm{s}(\square)$, and $1 \mathrm{~ms}(\boldsymbol{\Delta})$. The solid lines indicate a linear dependence of the number of charges collected on the fluence. In the TDCF experiments the bias was $V_{B}=+1.08 \mathrm{~V}$.

At high excitation density [Fig. 5(b)], the number of collected charges is a factor of 5 higher than at low excitation density. Again a power law decay is found with exponent $\alpha=\sim 0.24$ for both $V_{B}=+1.04$ and $0 \mathrm{~V}$. Thus, despite a laser fluence that is more than two orders of magnitude higher, very similar values for the exponent $\alpha$ are observed. This is consistent with conclusion drawn above stating that the recombination of the long lived carriers is not limited by the rate of bimolecular encounter of nongeminate electrons and holes in the window of observation. The results shown here may be compared to those reported by Mozer et al. ${ }^{12}$ who found that at $T=120 \mathrm{~K}$ the long lived carriers decay with exponent $\alpha=0.4$. Because $\alpha$ is temperature dependent, the difference in the values for $\alpha$ may be attributed to a difference in temperature.

In contrast to the low temperature case where no rate limiting bimolecular process could be observed, the decay of the long lived charges at room temperature shows the signatures of nongeminate electron-hole pair recombination. In Fig. 6 the dependence of the collection yield on time delay at room temperature is plotted. The average lifetime is now much shorter and the total yield significantly less than at $80 \mathrm{~K}$.

For times longer than $1 \mu \mathrm{s}$, the decay of the number of carriers approaches $1 / t$. This is in agreement with observations by Mozer et al. ${ }^{12}$ and indicates that the recombination is rate limited by a bimolecular process for which $n(t)$ $\sim 1 / t$, is predicted for large $t$. This indicates that at room temperature, the extractable long lived charge carriers are not 


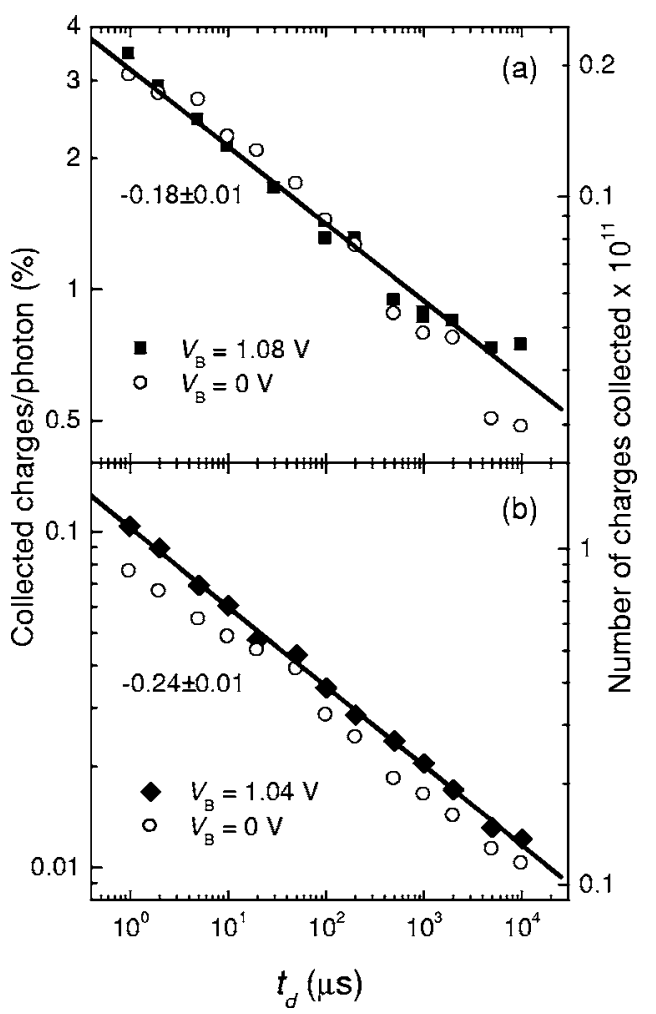

FIG. 5. Collected charges per incident photon for MDMO-PPV:PCBM devices at $80 \mathrm{~K}$ measured with TDCF as a function of delay time $t_{d}$ for excitation densities of (a) $4 \mu \mathrm{J} / \mathrm{cm}^{2}$ and (b) $750 \mu \mathrm{J} / \mathrm{cm}^{2}$. The applied bias $V_{B}$ varied as indicated in the inset. The magnitude of the collection voltage pulse was $V_{\text {coll }}=-4 \mathrm{~V}$. The yields obtained when a constant dc bias of $-4 \mathrm{~V}$ was applied were $25 \%$ at $4 \mu \mathrm{J} / \mathrm{cm}^{2}$ and $0.49 \%$ at $750 \mu \mathrm{J} / \mathrm{cm}^{2}$.

present in the form of Coulombically bound electron-hole pairs. If we compare the yield for delayed and prompt extraction of carriers at the two temperatures studied, it follows that at constant of $-4 \mathrm{~V}$ bias, temperature has little influence on the yield. Therefore the low yield for delayed collection of carriers at room temperature must be due to rapid recombination in the time interval between the moment, at which immediate carrier extraction occurs and the delay time of the collection.

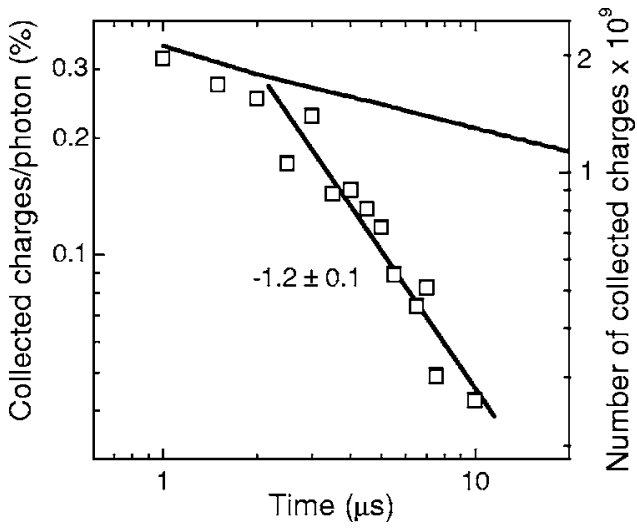

FIG. 6. Time dependence of the collected charges per incident photon $(\square)$ at room temperature. Parameters: $V_{B}=0.76 \mathrm{~V}, V_{\text {coll }}=-4 \mathrm{~V}$, and excitation density of $4 \mu \mathrm{J} / \mathrm{cm}^{2}$. The yield of the collected carriers at constant dc bias of $-4 \mathrm{~V}$ at room temperature is $25 \%$. For comparison, the data at $80 \mathrm{~K}$ [Fig. 4(a)] are also plotted (dashed line, scaled by a factor of 0.1 ).

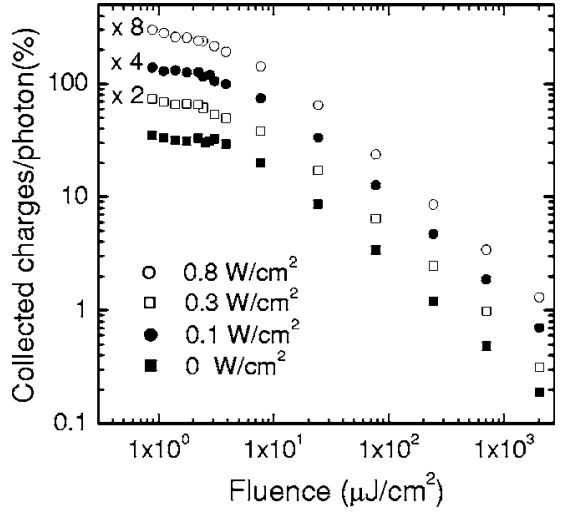

FIG. 7. Fluence dependence of the collected charges per incident photon under constant bias of $-4 \mathrm{~V}$ at $80 \mathrm{~K}$ for different background illumination intensities (shown in the inset). The curves are offset for clarity by multiplication with 2,4 , and 8 , as indicated.

Applying a bias $V_{B}=0 \mathrm{~V}$ at room temperature, results in a signal for the extracted delayed carriers that is too weak to be measured. This shows that the residence time of the photogenerated carriers at room temperature strongly depends on $V_{B}$. The large direct photocurrent observed indicates that a considerable number of charge carriers leaves the device via the contacts when $V_{B}=0 \mathrm{~V}$.

\section{Effect of background illumination}

Pulsed excitation as used in TDCF does not reflect the continuous illumination as experienced by solar cell devices under working conditions. To mimic this condition we have performed TDCF experiments in the presence of continuous white-light background illumination $\left(0-0.8 \mathrm{~W} / \mathrm{cm}^{2}\right)$. In a set of control experiments we first established that background illumination has a negligible effect on the number of collected charges under constant bias of $-4 \mathrm{~V}$ during excitation and collection (Fig. 7).

The influence of the background illumination on the long lived carriers detected by TDCF is shown in Fig. 8. Without background illumination a power law $\sim t^{-\alpha}$ is observed, with exponent $\alpha=\sim 0.2-0.3$. With increasing background illumination an increase of the exponent $\alpha$ is found up to $\alpha=$ $\sim 0.6$ for $0.6 \mathrm{~W} / \mathrm{cm}^{2}$ illumination. The effect of background illumination does not change significantly when applying higher pump fluences [750 $\mu \mathrm{J} / \mathrm{cm}^{2}$ vs $4 \mu \mathrm{J} / \mathrm{cm}^{2}$, Fig. 8(b)]. A reduction of the lifetime of the long lived carriers by a constant background illumination has also been observed by Nogueira et al. using optical detection methods. ${ }^{18}$ The faster recombination in the presence of background illumination can be explained in various ways: (i) recombination between the laser- and background light-induced charges, (ii) detrapping of the photogenerated charges by absorption of the background illumination, and (iii) filling of trap states by the charges induced by background illumination; traps that are already occupied, cannot be filled by the laser induced charges resulting in a shorter lifetime for the laser induced charges. This explanation is further investigated below and from the observed reduction of the lifetime we can estimate the number of low energy sites. 


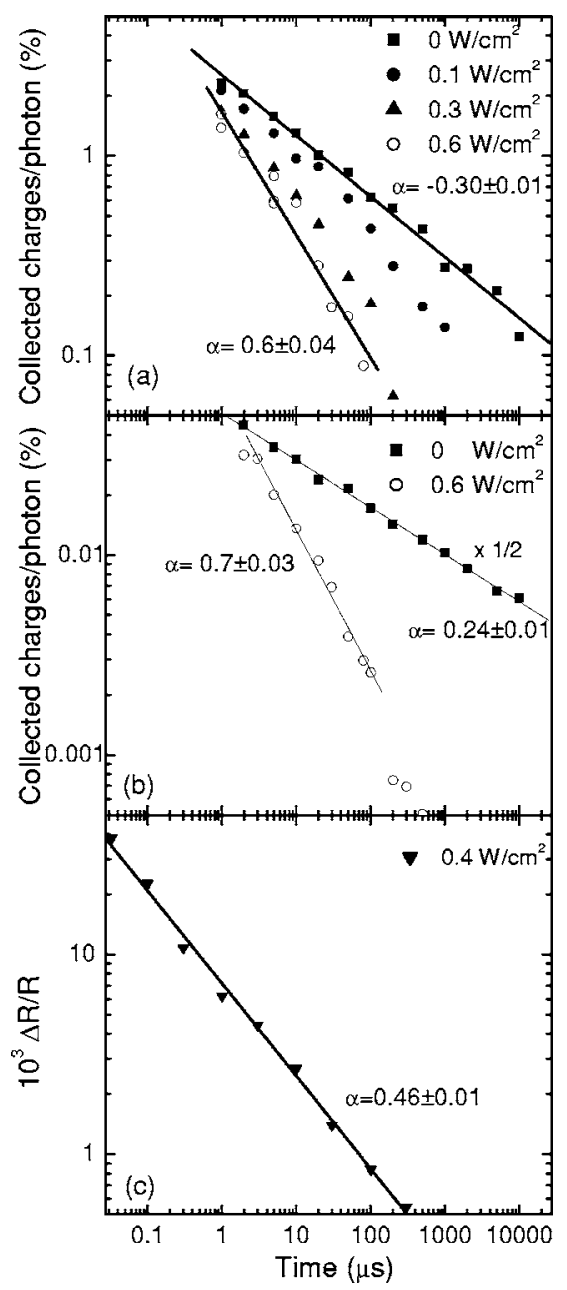

FIG. 8. (a) Time dependence of the collected charges per incident photon for different background illumination densities. Parameters: $V_{B}=+1.13 \mathrm{~V}$, $V_{\text {coll }}=-4 \mathrm{~V}$, excitation density of $4 \mu \mathrm{J} / \mathrm{cm}^{2}$, and $T=80 \mathrm{~K}$. The solid lines show a fit of a power law $\left(\propto t^{-\alpha}\right)$ to the data. (b) Same as in (a) except for the excitation density of $750 \mu \mathrm{J} / \mathrm{cm}^{2}$. (c) Decay of the photoinduced bleaching of a photovoltaic device measured in reflection mode and probed at $2.1 \mathrm{eV}$ photon energy, under the application of a constant bias $V_{B}=+1 \mathrm{~V}$. Excitation of $2.76 \mathrm{eV}$, pump fluence of $\sim 1 \mathrm{~mJ} / \mathrm{cm}^{2}$, and $T=80 \mathrm{~K}$. Background illumination of $0.4 \mathrm{~W} / \mathrm{cm}^{2}$.

The power conversion efficiency under tungsten halogen illumination by a MDMO-PPV-PCBM bulk heterojunctions is typically $>2 \%$ at room temperature. The efficiency of generation of a carrier with lifetime $>100 \mu$ s amounts to $1 \%$ [at low fluence at $80 \mathrm{~K}$, Fig. 4(b)]. From the reduction of the lifetime shown in Fig. 8 it follows that at $0.6 \mathrm{~W} / \mathrm{cm}^{2}$, all trap sites with a carrier lifetime $>100 \mu$ s are occupied as the signal of the long lived carrier vanishes at this delay. At room temperature the charge generation rate under $0.1 \mathrm{~W} / \mathrm{cm}^{2}$ tungsten halogen illumination is typically $5 \mathrm{~mA} / \mathrm{cm}^{2}{ }^{30}$ Assuming the same charge generation rate at low temperature, ${ }^{31}$ the steady state concentration of charge carriers with a lifetime exceeding $>100 \mu$ s generated from $0.6 \mathrm{~W} / \mathrm{cm}^{2}$ can be calculated in a straightforward manner and amounts to $>7$ $\times 10^{16} \mathrm{~cm}^{-3}{ }^{32}$ Because all trap sites are filled at $0.6 \mathrm{~W} / \mathrm{cm}^{2}$, the number of trap sites with carrier lifetime $>100 \mu$ s can be estimated at $10^{17} \mathrm{~cm}^{-3}$. This estimate is in agreement with previous study using near steady state photoinduced absorption $\left(10^{17} \mathrm{~cm}^{-3}\right)$ (Ref. 33) and nanosecond spectroscopy. ${ }^{19}$
The limiting behavior for the number of directly extracted carriers may also be due to availability of low energy sites.

Apart from the extraction methods described above, charge carriers can also be detected optically. The presence of a charge carriers induces bleaching of the ground state absorption band of the MDMO-PPV and measurement of the photoinduced bleaching as a function of time after a short excitation pulse can be used to determine the decay of the number of long lived photoinduced carriers. ${ }^{20,33}$ Here the sample is illuminated continuously with light from a tungsten halogen lamp to probe the bleaching. The measurements show a power law $t^{-\alpha}$ decay with exponent $\alpha=0.5$ at low temperature, applying a $V_{B}=+1 \mathrm{~V}$ bias voltage [Fig. 8(c)]. As described above, TDCF measurements also indicate a power law type with an exponent that depends in the background illumination. Comparing the results for the electrical and optical detection methods, the power law decay observed optically with $0.4 \mathrm{~W} / \mathrm{cm}^{2}$ matches reasonably well with the with TDCF data for $0.3 \mathrm{~W} / \mathrm{cm}^{2}$ background illumination. Therefore the two detection methods give essentially the same result, which indicates that the two methods probe largely the same set of long lived carriers.

\section{CONCLUSIONS}

Time delayed collection field experiments have been used to follow the recombination kinetics of photogenerated charge carriers in MDMO-PPV:PCBM solar cells at $80 \mathrm{~K}$ and at room temperature. At low temperature, the measurements do not support a recombination mechanism in which the overall rate is limited by the frequency of electron-hole encounter at the internal interface of the heterojunction. Instead, the recombination rate may be limited by monomolecular steps occurring before electron and hole come closer than the Onsager radius. Alternatively, the recombination may also be rate limited by processes within the Coulomb correlated electron-hole pairs. In contrast, at room temperature the decay kinetics provide clear evidence that the extractable carriers have escaped from the mutual Coulomb attraction. This may be explained by a screening of the Coulomb interaction or by a mechanism, in which the carriers are transported over considerable distances right after the electron transfer reaction, reaching mutual distances beyond the Onsager radius. At low temperature both the photoinduced absorption and the delayed collection method reveal a decay of the number of long lived carriers according to a power law $\left(t^{-\alpha}\right)$ with an exponent that is independent of the excitation density. Taking into account the effect of the background illumination used as a probe in the induced absorption measurement the magnitude of the exponent obtained by the optical and electrical detection methods correspond. This suggests that at low temperature both methods probe largely the same set of long lived carriers.

\section{ACKNOWLEDGMENTS}

The work of one of the authors (T.O.) forms part of the research program of the Dutch Polymer Institute (DPI), project DPI No. 324. The research of another author 
(S.C.J.M.) has been made possible by a fellowship of the Royal Dutch Academy of Arts and Sciences.

${ }^{1}$ J. J. M. Halls, C. A. Walsh, N. C. Greenham, E. A. Marseglia, R. H. Friend, S. C. Moratti, and A. B. Holmes, Nature (London) 376, 498 (1995).

${ }^{2}$ G. Yu, J. Gao, J. C. Hummelen, F. Wudl, and A. J. Heeger, Science 270 1789 (1995).

${ }^{3}$ P. Schilinsky, C. Waldauf, and C. J. Brabec, Appl. Phys. Lett. 81, 3885 (2002).

${ }^{4}$ F. Padinger, R. S. Rittberger, and N. S. Sariciftci, Adv. Funct. Mater. 13, 85 (2003).

${ }^{5}$ M. M. Wienk, J. M. Kroon, W. J. H. Verhees, J. Knol, J. C. Hummelen, P. A. van Hal, and R. A. J. Janssen, Angew. Chem., Int. Ed. 42, 3371 (2003).

${ }^{6}$ A. C. Morteani, P. Sreearunothai, L. M. Herz, R. H. Friend, and C. Silva, Phys. Rev. Lett. 92, 247402 (2004).

${ }^{7}$ T. Offermans, P. A. van Hal, S. C. J. Meskers, M. M. Koetse, and R. A. J. Janssen, Phys. Rev. B 72, 045213 (2005).

${ }^{8}$ H. Kim, J. Y. Kim, S. H. Park, K. Lee, Y. Jin, J. Kim, and H. Suh, Appl. Phys. Lett. 86, 183502 (2005)

${ }^{9}$ V. D. Mihailetchi, L. J. A. Koster, J. C. Hummelen, and P. W. M. Blom, Phys. Rev. Lett. 93, 216601 (2004).

${ }^{10}$ A. J. Mozer, N. S. Sariciftci, L. Lutsen, D. Vanderzande, R. Österbacka, M. Westerling, and G. Juska, Appl. Phys. Lett. 86, 112104 (2005).

${ }^{11}$ G. Dennler, A. J. Mozer, G. Juška, A. Pivrikas, R. Österbacka, A. Fuchsbauer, and N. S. Sariciftci, Org. Electron. 7, 229 (2006).

${ }^{12}$ A. J. Mozer, G. Dennler, N. S. Sariciftci, M. Westerling, A. Pivrikas, R. Osterbacka, and G. Juska, Phys. Rev. B 72, 035217 (2005).

${ }^{13}$ G. Juska, K. Arlauskas, M. Viliunas, K. Genevicius, R. Österbacka, and H Stubb, Phys. Rev. B 62, R16235 (2000).

${ }^{14}$ R. Österbacka, A. Pivrikas, G. Juska, K. Genevicius, K. Arlauskas, and H. Stubb, Curr. Appl. Phys. 4, 534 (2004).

${ }^{15}$ J. K. J. van Duren, X. Yang, J. Loos, C. W. T. Bulle-Lieuwma, A. B. Sieval, J. C. Hummelen, and R. A. J. Janssen, Adv. Funct. Mater. 14, 425 (2004).

${ }^{16}$ L. A. J. Koster, V. D. Mihailetchi, and P. W. M. Blom, Appl. Phys. Lett. 88, 052104 (2006)

${ }^{17}$ I. Montanari, A. F. Nogueira, J. Nelson, J. R. Durrant, C. Winder, M. A.
Loi, N. S. Sariciftci, and C. Brabec, Appl. Phys. Lett. 81, 3001 (2002).

${ }^{18}$ A. F. Nogueira, I. Montanari, J. Nelson, J. R. Durrant, C. Winder, N. S. Sariciftci, and C. Brabec, J. Phys. Chem. B 107, 1567 (2003).

${ }^{19}$ J. Nelson, S. Choulis, and J. R. Durrant, Thin Solid Films 451-452, 508 (2004).

${ }^{20}$ T. Offermans, S. C. J. Meskers, and R. A. J. Janssen, J. Chem. Phys. 119, 10924 (2003).

${ }^{21}$ J. Mort, I. Chen, A. Troup, M. Morgan, J. Knights, and R. Lujan, Phys. Rev. Lett. 45, 1348 (1980).

${ }^{22}$ J. Mort, A. Troup, M. Morgan, S. Grammatica, J. C. Knights, and R. Lujan, Appl. Phys. Lett. 38, 277 (1981).

${ }^{23}$ H. Naito and M. Okuda, J. Appl. Phys. 73, 1246 (1993).

${ }^{24}$ Z. D. Popovic, J. Chem. Phys. 78, 1552 (1983).

${ }^{25}$ M. Weiter and H. Bässler, J. Lumin. 112, 363 (2005).

${ }^{26}$ R. Österbacka, A. Pivrikas, G. Juska, K. Genevicius, K. Arlauskas, and H. Stubb, Curr. Appl. Phys. 4, 534 (2004).

${ }^{27}$ M. Esteghamatian, Z. D. Popovic, and G. Xu, J. Phys. Chem. 100, 13716 (1996).

${ }^{28}$ D. Hertel, E. V. Soh, H. Bässler, and L. J. Rothberg, Chem. Phys. Lett. 361, 99 (2002).

${ }^{29}$ I. H. Campbell, D. L. Smith, C. J. Neef, and J. P. Ferraris, Phys. Rev. B 64, 035203 (2001).

${ }^{30}$ L. J. A. Koster, V. D. Mihailetchi, H. Xie, and P. W. M. Blom, Appl. Phys. Lett. 87, 203502 (2005).

${ }^{31} \mathrm{Also}$ at low temperature the fluorescence from the MDMO-PPV:PCBM layer is almost completely quenched, suggesting photoinduced electron transfer with unit efficiency.

${ }^{32}$ The steady state number density of long lived charges is calculated as follows: $N=(\alpha / l)\left(\phi_{L} / \phi_{S}\right) \tau$, with $\alpha$ the charge generation rate calculated from the short circuit current under tungsten halogen illumination at room temperature, $l$ the thickness of the active layer, $\phi_{L}$ the number of long lived carriers per incident photon extracted at $t=100 \mu \mathrm{s}$ at low fluence $\left(\leqslant 2 \mu \mathrm{J} / \mathrm{cm}^{2}\right.$, see Fig. 4$), \phi_{S}$ the number of carriers per incident photon extracted under constant bias $(-4 \mathrm{~V})$ at low fluence $\left(\leqslant 2 \mu \mathrm{J} / \mathrm{cm}^{2}\right.$, see Fig. 4 ), and $\tau$ the lifetime of the long lived carriers that can be extracted after $100 \mu \mathrm{s}(>100 \mu \mathrm{s})$.

${ }^{33}$ T. Offermans, S. C. J. Meskers, and R. A. J. Janssen (unpublished). 